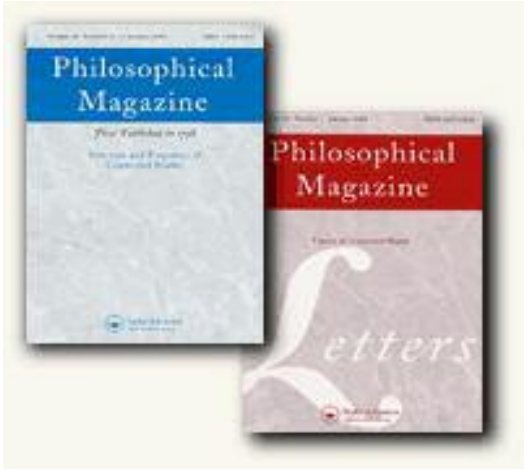

\title{
Heavy-ion Irradiations of Fe and Fe-Cr Model Alloys Part 2: Damage evolution in thin-foils at higher doses
}

\begin{tabular}{|c|c|}
\hline Journal: & Philosophical Magazine \& Philosophical Magazine Letters \\
\hline Manuscript ID: & TPHM-08-Feb-0047.R1 \\
\hline Journal Selection: & Philosophical Magazine \\
\hline $\begin{array}{r}\text { Date Submitted by the } \\
\text { Author: }\end{array}$ & 15-Jul-2008 \\
\hline Complete List of Authors: & $\begin{array}{l}\text { Hernández-Mayoral, Mercedes; CIEMAT, Division of Materials } \\
\text { Yao, Zhongwen; University of Oxford, Materials } \\
\text { Jenkins, Mike; University of Oxford, Materials } \\
\text { Kirk, Mark; Argonne National Laboratory, Materials Science }\end{array}$ \\
\hline Keywords: & in-situ electron microscopy, radiation damage \\
\hline Keywords (user supplied): & FeCr alloys \\
\hline \multicolumn{2}{|c|}{$\begin{array}{l}\text { Note: The following files were submitted by the author for peer review, but cannot be converted } \\
\text { to PDF. You must view these files (e.g. movies) online. }\end{array}$} \\
\hline $\begin{array}{l}\text { video } 1 \text { paper } 2 . \mathrm{mpg} \\
\text { video } 2 \text { paper } 2 . \mathrm{mpg} \\
\text { video } 3 \text { paper } 2 . \mathrm{mpg} \\
\text { video } 4 \text { paper } 2 . \mathrm{mpg} \\
\text { video } 5 \text { paper } 2 . \mathrm{mpg} \\
\text { video } 6 \text { paper } 2 . \mathrm{mpg} \\
\text { video } 7 \text { paper } 2 . \mathrm{mpg}\end{array}$ & \\
\hline
\end{tabular}

\section{s) ScholarONE" \\ Manuscript Central}




\section{Heavy-ion Irradiations of Fe and Fe-Cr Model Alloys}

\section{Part 2: Damage evolution in thin-foils at higher doses}

M. Hernández-Mayoral ${ }^{*}$, Z. Yao ${ }^{* *}$, M. L. Jenkins ${ }^{* * 1}$ and M. A. Kirk ${ }^{* * *}$

*Division of Materials. CIEMAT Avenida Complutense, 22, 28040-Madrid

** Department of Materials, University of Oxford, Parks Rd., OX1 3PH

${ }^{* * *}$ Materials Science Division, Argonne National Laboratory, Argonne, IL 60439

${ }^{1}$ Corresponding author: Email mike.jenkins@materials.ox.ac.uk 


\section{Abstract}

We continue our study of heavy-ion damage in $\mathrm{Fe}$ and $\mathrm{FeCr}$ alloys started in Part 1[1] with an investigation of damage development in UHP Fe and $\mathrm{Fe} 8 \% \mathrm{Cr}$ at higher doses up to $2 \times 10^{19}$ ions $\mathrm{m}^{-2}$ ( $\sim 13 \mathrm{dpa}$ ). In thin-foil irradiations with $150 \mathrm{keV} \mathrm{Fe}{ }^{+}$ions at $300^{\circ} \mathrm{C}$ and room temperature (RT), more complex microstructures started to develop in thicker regions of the foils at doses greater than about $2 \mathrm{x}$ $10^{18}$ ions $\mathrm{m}^{-2}$, seeming to involve cooperative interaction, alignment and coalescence of smaller loops. First strings of loops all with the same $1 / 2<111>$ Burgers vectors formed. In UHP Fe irradiated at $300^{\circ} \mathrm{C}$ the damage then developed into colonies of resolvable interstitial loops with $1 / 2<111>$ Burgers vectors. By a dose of $2 \times 10^{19}$ ions $\mathrm{m}^{-2}$, large (several hundred nanometre) finger-shaped loops with large shear components had developed by the growth and subsequent coalescence of smaller loops. Similar but finer-scale damage structures developed in UHP Fe irradiated at RT and in $\mathrm{Fe} 8 \% \mathrm{Cr}$ irradiated at both $\overline{\mathrm{RT}}$ and $300^{\circ} \overline{\mathrm{C}}$.

Keywords: heavy-ion irradiation, FeCr alloys, in-situ TEM 


\section{Introduction}

In Yao et al [1], hereafter called Part 1, we described the evolution of radiation damage under heavy-ion irradiation at room temperature (RT) and $300^{\circ} \mathrm{C}$ in thin foils of pure Fe of different purities and a range of $\mathrm{FeCr}$ alloys at doses up to $2 \times 10^{18}$ ions $\mathrm{m}^{-2}$ In this paper we continue with a description of the damage structures which evolved at higher doses up to $2 \times 10^{19}$ ions $\mathrm{m}^{-2}$ in ultra high-purity $\mathrm{Fe}$ (UHP Fe) and Fe8wt.\% $\%$ under $150 \mathrm{keV} \mathrm{Fe}$ irradiation at $300^{\circ} \overline{\mathrm{C}}$ and at $\overline{\mathrm{RT}}$.

\section{\$2 Experimental details}

| The UHP Fe and the Fe8wt.\%Cr alloys were the same materials described in Part 1. Both were polycrystalline materials with the majority of grains oriented within $0-15^{\circ}$ of (111). The experimental methods were also largely the same. Specimens were investigated in both ex-situ TEM and in-situ experiments. In ex-situ experiments, specimens of UHP Fe were irradiated with $150 \mathrm{keV} \mathrm{Fe}^{+}$ions at $\underline{300^{\circ} \mathrm{C} \text { in the CSNSM Facility in Orsay, France to doses from } 10^{18} \text { to } 2 \times 10^{19} \text { ions } \mathrm{m}^{-2} \text { at a dose rate of } 4}$ $\underline{x} 10^{15}$ ions $\mathrm{m}^{-2} \mathrm{~s}^{-1}$. They were returned to CIEMAT in Madrid for examination in a JEOL 2010 transmission electron microscope. In-situ experiments were carried out on the Argonne IVEM-Tandem Facility, as described in Part 1. Specimens of UHP Fe and Fe $\%$ Cr were irradiated with $150 \mathrm{keV} \mathrm{Fe}^{7}$ ions at $300^{\circ} \mathrm{C}$ or RT to maximum doses of about $2 \times 10^{19}$ ions $\mathrm{m}^{-2}$. The depth of the peak damage for $150 \mathrm{keV} \mathrm{Fe}$ irradiation is at about $28 \mathrm{~nm}$ and damage extends to a maximum depth of about $100 \mathrm{~nm}$. A dose $2 \times 10^{19} \mathrm{~m}^{-2}$ of $150 \mathrm{keV} \mathrm{Fe}$ ions gives a maximum damage level of $13 \mathrm{dpa}$. The maximum dose in the in-situ experiments was limited by the accelerator ion source lifetime, and it was not always possible to reach $2 \times 10^{19}$ ions $\mathrm{m}^{-2}$. The evolution of damage over the whole dose range was followed by recording images dynamically under weak-beam diffraction conditions. The irradiation was carried out in several dose steps, and after each step micrographs were recorded on film or CCD. After the maximum dose was achieved the specimens were allowed to cool to room temperature (if irradiated at $300^{\circ} \mathrm{C}$ ) for further detailed microscopy.

Due to the development of larger, more complex damage structures, more complete diffraction contrast experiments were performed than at lower doses. For example, in the experiment in UHP Fe at $300^{\circ} \mathrm{C}$ described in $\S 3.1$ we succeeded in tilting a specimen oriented about midway between the [111] and [110] poles to both of these poles, as well as to the [311] and [131] poles. Both weak-beam and bright-field kinematical (BFK) micrographs were taken in all available reflections. The $|\mathbf{g} . \mathbf{b}|$ table for this experiment is given in table 1, and shows that a complete analysis of Burgers vectors is possible. In most cases micrographs were taken with both $+\mathbf{g}$ and $-\mathbf{g}$. It was then possible to deduce the vacancy or interstitial nature of resolvable loops from their inside-outside contrast behaviour (for details see [2]). In other cases it was not possible to carry out such an extensive analysis because of difficulties in | tilting ferromagnetic specimens, but less extensive experiments still proved informative.

\section{$\S 3 \quad$ Results}

3.1 UHP Fe irradiated at $300^{\circ} \mathrm{C}$

Figure 1 shows an overview of damage development in ex-situ experiments over a dose range of $2 \times 10^{18}$ ions $\mathrm{m}^{-2}$ to $2 \times 10^{19-}$ ions $\mathrm{m}^{-2}(1.3-13 \mathrm{dpa})$. The micrographs were taken in a moderately thick $(60-100 \mathrm{~nm})$ area of foil. They should be compared with the micrographs presented in Part 1 (e.g.

\begin{tabular}{|c|}
\hline Deleted: $(\sim 1 \mathrm{dpa})$. \\
\hline $\begin{array}{l}\text { Deleted: In all these experiments the } \\
\text { damage took the form of small }(2-5 \mathrm{~nm}) \\
\text { dislocation loops with Burgers vectors } \mathbf{b} \\
=1 / 2<111>\text { or }<100>\text {. Loops were seen } \\
\text { only at cascade overlap doses. There was } \\
\text { evidence that some at least of the loops } \\
\text { were vacancy in nature. Loop number } \\
\text { densities } \mathrm{N} \text { increased with dose } \varphi \text { at a rate } \\
\mathrm{N}=\varphi^{\mathrm{n}} \text { with } \mathrm{n} \approx 0.7 \sim 2 \text { depending on } \\
\text { material and irradiation conditions. The } \\
\text { main effect of Cr seemed to be in } \\
\text { reducing loop mobilities. Less loop } \\
\text { "hopping" was seen in FeCr alloys than } \\
\text { in pure Fe, and fewer loops were lost to } \\
\text { the foil surfaces. The irradiation } \\
\text { temperature also affected loop mobilities: } \\
\text { more loop hopping was seen at } 300^{\circ} \mathrm{C} \\
\text { than at RT and this led to greater loss of } \\
\text { loops at the higher temperature. }\end{array}$ \\
\hline Deleted: in thin foils \\
\hline Formatted: Indent: First line: $0.5 "$ \\
\hline Formatted: Font: Italic \\
\hline $\begin{array}{l}\text { Deleted: Again specimens were } \\
\text { investigated by both } e x \text {-situ TEM and in- } \\
\text { situ experiments using the }\end{array}$ \\
\hline Deleted: Irradiations were carried out \\
\hline Deleted: \\
\hline Deleted: \\
\hline Deleted: 12 \\
\hline Deleted: (see Part1). \\
\hline Deleted: As described in Part 1 [1] a \\
\hline Deleted: of \\
\hline
\end{tabular}

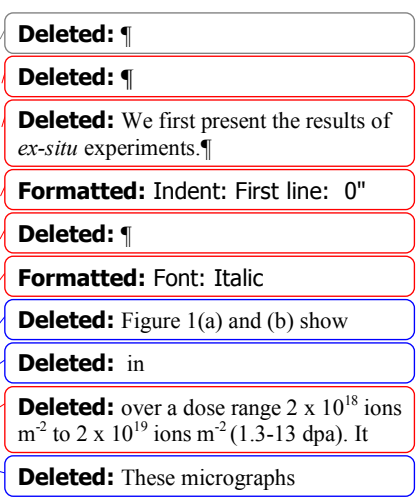


developed into resolvable loops was captured in video 3 , which shows an UHP Fe specimen irradiated at $300^{\circ} \mathrm{C}$ over a dose range 6.5 to $6.6 \times 10^{18}$ ions $\mathrm{m}^{-2}$. Figure 4 shows a series of frames extracted from this video.

With further irradiation these loops grew, Figure $3(\mathrm{~d})$. Video 4 shows that this growth process was not uniform. Figure 5 shows several video frames, although the video itself should be viewed to appreciate the whole process. Individual loops seemed to flex or "breathe", and gradually increased in size, although occasionally individual loops shrank significantly for a time before continuing to grow. Small white dots (in these weak-beam images) were frequently seen decorating larger resolved loops | (see e.g. the arrowed features in the left-hand panel of Figure 5). The contrast of these decorating features always faded after some time, suggesting that the climb of larger loops involved the assimilation of smaller loops, perhaps by a change of Burgers vector (see subsequent panels of Figure $(5)^{\frac{3}{}}$. However, increases and decreases in loop size - flexing - occurred without the obvious involvement of smaller loops. Large loops often developed in lines, sometimes along or close to $<110>$ directions.

When loops overlapped they sometimes coalesced to form larger finger-shaped loops, often several hundred nanometres in length and several tens of nanometres in width (Figure 5, and video 4). Generally loops lay entirely in the specimen, despite reaching these large sizes. Occasionally loops intersected the foil surface. Even more occasionally large loops were seen to glide out of the foil (see also section 3.3, and video 7). There was a tendency for finger-shaped loops to align close to $<110>$ directions, as in Figure 1(b). However the particular direction in which they aligned in a given area tended to be such that the long-axis of the loops pointed towards the hole in the wedge-shaped foil, that is $_{2}$ in the direction of the thickness gradient (see Figure 1(c)).

Figure 6 shows some representative BFK micrographs selected from the full diffraction contrast experiment which was performed at the end of the irradiation (table 1). The foil normal was oriented about $15^{\circ}$ away from the [111] pole in the direction of the [110] pole as shown schematically in the | stereogram of Figure 7. This area contained three sets of large loops, members of which are labeled A, $\mathrm{B}$ and $\mathrm{C}$. Set $\mathrm{A}$ had developed in this region into elongated finger-like loops such as those seen in Figures 1(c) and 5, although in this area they are not as dominant. Sets B and C comprise more isolated rounded loops. Smaller loops visible as dark dots are also present. There are also dark dots decorating the larger loops. Loop sets $\mathrm{A}$ and B are visible in Figure 6(a) and (d), which show a $\pm \mathbf{g}$ pair with $\mathbf{g}=$ $\overline{1} 10$ taken close to the [111] pole. The finger-loops marked A show outside contrast in Figure 6(a) with $\mathbf{g}=\overline{1} 10$ and inside contrast in figure $6(\mathrm{~d})$ in $\mathbf{g}=1 \overline{1} 0$. The second set of more rounded large loops B show the reverse contrast. Inside-outside contrast was also observed in two other reflections, not shown here. The set of loops $A$ is out of contrast in Figure $6(\mathrm{~b})$ with $\mathbf{g}=01 \overline{1}$ but is visible in all the other micrographs here. The full contrast experiment found that set A was also out of contrast in $\mathbf{g}=1 \overline{1} 2$, and so confirms that the Burgers vector of these loops is $\mathbf{b}= \pm 1 / 2[\overline{1} 11]$. Similarly the Burgers vector of loop set $\mathrm{B}$ which is out-of-contrast in $\mathbf{g}=10 \overline{1}$ (Figure $6(\mathrm{c})$ ) and $\mathbf{g}=112$ (not shown) is $\mathbf{b}=$ $\pm 1 / 2[1 \overline{1} 1]$. The third set of rounded loops $\mathrm{C}$ is out-of-contrast in Figure $6(\mathrm{a})$ and (d) but can be seen in Figures $6(\mathrm{~b}, \mathrm{c}$ and $\mathrm{e})$ and so has $\mathbf{b}= \pm 1 / 2[11 \overline{1}]$. These Burgers vectors are also shown on the

${ }^{3}$ Climb of pre-existing line dislocations also seemed to involve interaction with and assimilation of small loops, see e.g. video 2 .

\begin{tabular}{|c|}
\hline Deleted: well \\
\hline Deleted: 5 \\
\hline Deleted: $\uparrow$ \\
\hline Deleted: 4 \\
\hline Deleted: 6 \\
\hline Deleted: 6 \\
\hline Deleted: 6 \\
\hline Deleted: 6 \\
\hline Deleted: . $\llbracket$ \\
\hline \multirow{3}{*}{$\begin{array}{l}\text { Deleted: } 9 \\
\text { Figure } 7 \text { shows loop alignment more } \\
\text { clearly. Here the same specimen seen in } \\
\text { Figure } 6 \text { has been tilted to [001], and a } \\
\text { nearby area showing more organized loop } \\
\text { alignment has been imaged under BFK } \\
\text { conditions. Lines of loops can be seen } \\
\text { along or close to the [ } 110 \text { ] direction } \\
\text { running diagonally from the top left, and } \\
\text { some have coalesced to form finger- } \\
\text { shaped loops, similar to those seen in } \\
\text { figure } 1 \text { (b). These loops belong to the set } \\
\text { designated A in the Burgers vector } \\
\text { analysis described below. The [ } 110 \text { ] } \\
\text { direction along which they align lies } \\
\text { close to the plane of the foil. The } \\
\text { tendency for alignment shown in this } \\
\text { micrograph may be exaggerated because } \\
\text { the foil has been tilted such that the loop } \\
\text { habit plane, which is close to the plane of } \\
\text { the foil, is inclined, see below. There is } \\
\text { some evidence for more limited } \\
\text { alignment in the perpendicular } \\
\text { [110], direction which is steeply inclined } \\
\text { to the foil plane, suggesting the formation } \\
\text { of a raft-like structure. } 9 \\
\text { ॠ }\end{array}$} \\
\hline \\
\hline \\
\hline Deleted: \\
\hline Deleted: , see Figure 8 \\
\hline Deleted: 9 \\
\hline Deleted: 10 \\
\hline Deleted: , \\
\hline Deleted: 6 \\
\hline Deleted: 7 \\
\hline Deleted: 9 \\
\hline Deleted: 9 \\
\hline Deleted: 9 \\
\hline Deleted: 9 \\
\hline Deleted: \\
\hline Deleted: 9 \\
\hline Deleted: 9 \\
\hline Deleted: 9 \\
\hline Formatted: English (U.K.) \\
\hline
\end{tabular}


stereogram. Attempts to determine the Burgers vectors of the smallest loops (visible only as small dots) were not successful.

Information on the habit planes of the loops was obtained from the changes in their projected | shapes when the foil was tilted to the various poles [111], [110], [311] [131] and [001]. The set of elongated loops A narrowed somewhat but did not become edge-on when the foil was tilted to [110] showing these loops do not lie on $(\overline{1} 11)$ and so are not of pure edge type. In fact they seem to lie close | to or on the (111) plane which is shallowly inclined about $15^{\circ}$ to the plane of the foil. Three other observations are consistent with these loops lying close to the foil plane. First, they grew to large sizes in both dimensions without intersecting the foil surface except in rare cases. Second, weak-beam | images of the loops showed no strong depth oscillations, so the bounding dislocations cannot be steeply inclined. Third, the projected shapes of loops which are elongated along [ $\overline{1} 10]$ when viewed along a | direction close to [001] is consistent with a habit plane close to (111). It was more difficult to determine the habit planes of the other sets of loops B and C, but most of these are also thought to have large shear components. The jagged shapes of some of the loops suggest however that they may not lie on a single plane, but are possibly stepped.

The nature of the loops was established from a knowledge of their Burgers vectors, habit planes and inside-outside contrast behaviour. For the orientations used for imaging the inside-outside contrast behaviour was expected to be the same as for an edge loop of the same Burgers vector (the loop normals $\mathbf{n}_{\mathrm{L}}$ lie within the region of the stereogram centred on the beam-direction $\mathbf{z}$ and bounded by the | great circles $\mathbf{n . b}=0$ and $\mathbf{n . z}=0$, see ref [2] p80 and Figure 7). In all cases the contrast changes of the large resolvable loops (sets A, B and C) were consistent with loops of interstitial nature.

Figure 8 shows evidence for the possible presence of small voids in a specimen irradiated at $300^{\circ} \mathrm{C}$ to a dose of $10^{19}$ ions $\mathrm{m}^{-2}$. These images were taken in a thin area of foil with the specimen oriented such that little diffraction contrast was present. Very small $(1-2 \mathrm{~nm})$ circular features are | present, which appear black in the over-focused image on the left and white in the under-focused image on the right. This is consistent with the contrast expected from small voids. Similar features were not present in unirradiated specimens, or in specimens irradiated to lower doses.

\subsection{UHP Fe irradiated at RT}

The initial stages of damage development were similar to the irradiation at $300^{\circ} \mathrm{C}$. Again at low doses small loops were produced homogeneously. Again the video (5) showed that small loops in thicker areas $\left(\geq 60 \mathrm{~nm}\right.$ ) were very mobile (although the frequency of hopping was less than at $300^{\circ} \mathrm{C}-$ | see Part 1.). At a dose of $10^{19}$ ions $\mathrm{m}^{-2}$ strings of loops had formed in thicker areas of foil (Figure 2). However these strings had not developed further when the irradiation was terminated at a dose of $1.6 \mathrm{x}$ $10^{19}$ ions $\mathrm{m}^{-2}(\sim 10 \mathrm{dpa})$. The specimen was then tilted to an [001] orientation. At this orientation the strings were visible as two more or less perpendicular sets, lying close to the 110 and 110 directions. $\underline{A}$ contrast experiment showed that each string consisted, of loops with the same $1 / 2<111>$ Burgers vector.

\subsection{Fe8\% Cr irradiated at $300^{\circ} \mathrm{C}$ and $\mathrm{RT}$,}

The evolution of the damage microstructures in $\mathrm{Fe} 8 \% \mathrm{Cr}$ is illustrated in Figure 10 (for the $300^{\circ} \mathrm{C}$ irradiation) and Figure 11 (for RT). In both cases the foil thickness was about $100 \mathrm{~nm}$. The damage evolution was qualitatively similar to damage evolution in UHP $\mathrm{Fe}$, and again was characterized first by the development of strings of loops at doses above about $10^{19}$ ions $\mathrm{m}^{-2}$ (see video




6 and Figures 10(a) and 11(a)) which further developed into resolvable dislocation loops at a dose of about $2 \times 10^{19}$ ions $\mathrm{m}^{-2}$ (Figures10(b) and 11(b)). Video 7 shows the loss of a large loop by glide from the foil which was seen only rarely. At $300^{\circ} \mathrm{C}$ there was evidence that oriented arrays of finger-like loops were starting to form (Figure $10(\mathrm{~b})$, although this was on a finer scale and not as obvious as in UHP Fe. Quantitative data on loop sizes and number densities for this condition are shown in table 2 . At the highest dose loops as large as $24 \mathrm{~nm}$ were present, but extensive loop coalescence had not taken place and loop number densities continued to increase, unlike the case of UHP Fe. In the RT irradiation at this dose ${ }_{2}$ loop strings, some of which had developed into a network of large resolvable loops, were present (Figure $11(\mathrm{~b})$ ).

\section{Discussion}

We are now in a position to speculate on the underlying radiation damage mechanisms leading to our observations. A first point to make is that our observations are limited by the resolution limit in diffraction contrast imaging. We see only clusters of size larger than about 1-2 nm (the lower limit depending on foil quality) and such clusters comprise of the order of 100 point defects. Smaller clusters are certainly present, probably in higher concentrations, but we are not able to observe these directly.

\section{The initial production of dislocation loops.}

In our experiments most point defects are created in high-energy cascades initiated by incoming ions. It has long been accepted that a likely result of the cascade process is the production of a vacancyrich core surrounded by a shell of interstitials. In many materials the vacancy-rich cores may collapse to form dislocation loops visible in the TEM. This does not seem to happen in Fe in cascades initiated by $\mathrm{Fe}^{+}$ions or Fe primary knock-on atoms $[3,4]$. Instead the vacancies may aggregate to form microvoids or loose vacancy sponges, not visible in the TEM but detectable by positron annihilation experiments, see e.g. [5]. It is now thought, on the basis of several molecular dynamics (MD) studies e.g.[6-8] that interstitial clustering also occurs spontaneously in cascades without the need for longrange diffusion. Experimental evidence for interstitial clustering in cascades in Fe is lacking, although small ( $\sim 3$ interstitial) clusters have been found in X-ray diffuse scattering experiments on neutronirradiated Al at temperatures below Stage I [9]. The interstitial clusters seen in MD simulations of cascades in Fe typically consist of a few to tens of interstitial atoms, again too small to be seen directly in the TEM. The stable configuration of these small clusters can be regarded as a set of $<111>$ crowdions. They are highly mobile in one dimension.

Our experiments are certainly not inconsistent with this picture. We see no defects of any kind at low doses where cascades are well separated spatially. This implies that clusters of visible size are not produced in individual cascades. Damage first appears at cascade overlap doses and takes the form of small 2-5 nm dislocation loops. We have presented evidence in Part 1 that at least some of these loops are created in a cascade process.

What is this cascade process? The production of vacancy loops by the collapse of individual cascades has been seen in experiments on pure $\mathrm{Fe}$ irradiated with $\mathrm{Xe}^{\mp}$ and other very heavy ions [10]. Cascade collapse is therefore possible in Fe, but probably only in cascades which result in higher I vacancy concentrations and energy densities than those produced by self-ions. It has been argued that the collapse of cascades initiated by self-ions can occur if the cascade occurs in a region populated with | sub-microscopic clusters remaining from earlier cascades, so-called cascade debris, see Part 1 and refs $[3,4]$. Our observations are again not inconsistent with this picture. The observation of small resolvable

Deleted:
Deleted: of a large loop
Deleted: 15
Deleted: c

\section{Deleted: 16}

Deleted: $\mathrm{d}$

Deleted: 9

Formatted: Numbered + Level: $1+$ Numbering Style: $1,2,3, \ldots+$ Start at: 4 + Alignment: Left + Aligned at: $0.25^{\prime \prime}+$ Tab after: $0.75^{\prime \prime}+$ Indent at: $0.75^{\prime \prime}$

Deleted:

Deleted: the
Deleted: This evidence includes: (1) the areal density of loops does not depend on the foil thickness (Part 1, Fig.4); and (2) the loops do not increase in size at doses below about $10^{18}$ ions $\mathrm{m}^{-2}$, that is before loop interactions and the development of a more complex microstucture (Part 1,

Figures 7 and 8 ). Of course both of these measurements were made from

micrographs taken after irradiation, and so exclude loops lost during irradiation.

Formatted: Font color: Blue

Deleted: We note that the 
voids at high doses suggests the presence of unresolved vacancy clusters at lower doses. In addition the time-dependence of loop formation reported in Part 1 suggests that loops grow by the diffusion of point-defects or small clusters from their immediate surroundings over a period of one or two tenths of a second. This is consistent with an initial collapse event leading to the production of a small loop. The | loop then grows by accretion of nearby vacancies within the cascade volume.

This loop formation process was envisaged for the production of vacancy loops at overlap | doses. Could a similar process result in the production of visible interstitial loops? There seems no reason to exclude this a priori, although it may seem less likely than vacancy loop formation, since cascade debris is likely to consist of small immobile vacancy clusters such as microvoids, but very mobile interstitial clusters which may leave the scene before the arrival of a subsequent cascade. Perhaps it is more likely that interstitial loops are formed by random encounters between migrating sub-microscopic interstitial clusters. The increase in cluster sizes at doses above $10^{18}$ ions $\mathrm{m}^{-2}$ (table 2) suggests that some clusters grow in this dose regime by diffusion and coalescence processes.

In our in-situ experiments we were not_able to determine the nature of the mobile loops directly. In Part 1, we showed that some of the loops in $\mathrm{Fe} 11 \% \mathrm{Cr}$ produced by $30 \mathrm{keV} \mathrm{Ga}^{-}$ion irradiation at overlap doses in a FIB are most likely vacancy in nature. However we also noted that the loops which we had analysed lay close to the foil surface (in the first depth layer) in foils of moderate thickness $(\leq 50 \mathrm{~nm})$. They were also fairly large in size and jmmobile. They may therefore not be typical of the whole population of loops seen in our experiments. It is likely that many if not most loops in this (111) foil would have been lost to the surface. This might include particularly interstitial loops with $\mathbf{b}=1 / 2<111>$ which are likely to be highly mobile. We conclude that vacancy loops are very likely to be present in our experiments, but we cannot exclude the possibility that interstitial loops are also formed, perhaps in comparable or even higher numbers. Abe et al [11] have argued that many of the small mobile clusters generated from individual displacement cascades in copper and gold by in-situ heavy-ion irradiation are of interstitial character. The interstitial nature of the clusters in these experiments was not determined directly but was inferred from their short lifetimes (a few thirtieths of a second - sessile vacancy clusters such as Frank loops or stacking-fault tetrahedra had much longer lifetimes).

\section{The development of loop strings,}

In thin regions of foil $(\leq 40 \mathrm{~nm})$ only isolated loops were seen at all doses, most with $<100>$ Burgers vectors. From the discussion above we speculate that these are relatively immobile vacancy loops, produced by a cascade overlap mechanism. At these foil thicknesses both of the surfaces act as strong sinks for the mobile interstitial clusters and large interstitial loops are unlikely to form. Probably some vacancy loops will also be lost to the surface However, at doses above about 2 X $10^{18}$ ions $\mathrm{m}^{-2}$ strings of loops appeared in thicker regions of foil. Loop strings consist typically of several small loops, all with the same $1 / 2<111>$ Burgers vector, and aligned roughly along $<110>$ directions. The formation | of these strings appeared to involve some sort of cooperative interaction between mobile loops.

The formation of loop strings seems similar to the early stages of raft formation, which is seen in many materials but is particularly prevalent in bcc metals, see e.g. [12-14]. Raft formation in irradiated materials has been discussed recently by Wen et al [15]. These authors found in Kinetic Monte Carlo simulations that raft formation can be achieved by the prismatic glide of one-dimensional (1-D) interstitial clusters and rotation of their Burgers vectors under the influence of internal strain
Deleted: point-defects

Formatted: Font: Italic

Deleted: 9
Deleted: very
Deleted: 40
Deleted: are
Deleted: very
Deleted: Many
Deleted: appears

\begin{tabular}{l} 
Deleted: have \\
Deleted: been \\
Deleted: are \\
Deleted: all \\
Deleted: very \\
Deleted: and \\
Deleted: are \\
Deleted: In this irradiation condition it \\
\hline
\end{tabular}


fields. We quote from Wen et al [15]: "Mutual elastic interactions between clusters was found to affect their distribution and motion drastically. Because of mutual interaction, two clusters that are oriented along non-parallel crystallographic directions will either coalesce forming a larger one or rotate and pin one another at a short distance and move jointly in the same direction. Once two clusters are pinned together, they have less chance to change their orientation, and therefore their motion becomes almost pure one-dimensional. As this process proceeds, some additional clusters may be trapped into this pinned structure by changing their Burgers vectors."

Wen et al's model appears to be a good description of our experimental observations, Several of its distinctive features are seen experimentally. These include:(1) the formation of strings by the interaction of mobile $1 / 2<111>$ loops. (2) the observation that small clusters of $2-3$ loops are still mobile, performing $1-\mathrm{D}$ motion although with reduced mobility, but that jarger clusters are immobile; and (3) the formation of groups of loops with the same Burgers vectors. The tendency of loops to form strings along $<110>$ directions is likely to be due to loop-loop elastic interactions, where loops adjust their orientations and positions in order to minimize the elastic interaction energy [16].

What is the nature of the loops which participate in this process? Loops of both vacancy and interstitial nature with $1 / 2<111>$ Burgers vectors are thought to be mobile, according to simulations by Gilbert et al [17]. However the large loops which develop from strings have been shown to be of interstitial nature. We therefore believe that the strings consist of small interstitial loops. Initially it would be expected that small interstitial clusters would move in 1-D. Such 1-D motion would result in little recombination with $\overline{\mathrm{V}}$ clusters $\mathrm{In}$ thin foils both surfaces act as sinks and most interstitial clusters will be lost. We envisage that in thicker regions of foil, some clusters penetrate to the foil interior, where they can grow and interact, Jeading to the formation of immobile strings.

\section{The development of large interstitial loops ,}

Video evidence suggests that loop strings evolve into resolvable loops. Loops form at the sites of loop clusters or strings, and both the resolvable loops and the loop strings have $1 / 2<111>$ Burgers vectors. Wen et al [15] find that groups of 5 or more loops are immobile and it seems reasonable to suppose that these strings act as the nuclei for large interstitial loops. The loops in the string would be expected to climb and coalesce by a similar mechanism seen for the larger loops as they develop into finger loops, as described below.

The changes in the shapes of loops as they grow - flexing - seems most likely to be due to glide of loops on their glide cylinders under the influence of stresses induced by the electron and ion beams. Note that the loops have large shear components - the finger-loops A analyzed in $\S 3$ lie close to the (111) plane but have Burgers vector $\mathbf{b}=1 / 2[\overline{1} 11]$, so that the angle between the loop normal $\mathbf{n}$ and $\mathbf{b}$ is about $70^{\circ}$. This implies that loop growth involves both glide and climb. Overall the tendency is for loops to grow larger in all dimensions, implying a net absorption of interstitials. Occasionally loops seemed to shrink, possibly when a vacancy cluster was absorbed, although again glide may be involved.

Loops may climb by absorbing either single point defects and sub-microscopic clusters or resolvable loops. In videos we see loop growth and shrinkage without any obvious involvement of smaller loops, and we take this as evidence of the first process. However, small mobile loops still form continuously during irradiation and can be assimilated by larger loops This process seems to involve

\begin{tabular}{|c|}
\hline Deleted: described above \\
\hline Deleted: We have seen directly that \\
\hline Deleted: appears to involve \\
\hline Deleted: s \\
\hline Deleted: between $1 / 2$ \\
\hline Deleted: mobile \\
\hline Deleted: . \\
\hline Deleted: Small \\
\hline Deleted: still \\
\hline Deleted: . Larger \\
\hline Deleted: (5 or more loops) become \\
\hline $\begin{array}{l}\text { Deleted: . Wen et al's process leads to } \\
\text { groups }\end{array}$ \\
\hline $\begin{array}{l}\text { Deleted: Most of these features are } \\
\text { seen in our experiments. }\end{array}$ \\
\hline Deleted: We note $\mathrm{h}$ \\
\hline $\begin{array}{l}\text { Deleted: that the next stage in } \\
\text { microstructural evolution is the } \\
\text { development }\end{array}$ \\
\hline Deleted: in the same regions \\
\hline Deleted: from strings \\
\hline Deleted: of large \\
\hline Deleted: interstitial \\
\hline Deleted: loops which \\
\hline $\begin{array}{l}\text { Deleted: } \uparrow \\
\text { Why do loop strings form only in thicker } \\
\text { regions of foil? This must be due to the } \\
\text { surfaces acting as strong sinks for small } \\
\text { mobile interstitial loops or crowdion } \\
\text { clusters. }\end{array}$ \\
\hline Deleted: loops \\
\hline $\begin{array}{l}\text { Deleted: Some loops would move to } \\
\text { the surface and be lost }\end{array}$ \\
\hline Deleted: I \\
\hline Deleted: will \\
\hline Deleted: their interaction leads \\
\hline Formatted: Indent: First line: $0 "$ \\
\hline Deleted: ף \\
\hline Deleted: analysed \\
\hline Formatted: Font: Bold \\
\hline Deleted: is \\
\hline
\end{tabular}


first the decoration of a larger loop by smaller loops, as seen in Figure 5. In the videos bright dots often appeared at the peripheries of large loops, then faded, suggesting absorption onto the dislocation line causing climb. Again this is consistent with the simulations of Wen et al [15]. In their study of dislocation decoration they find that small clusters are often trapped near the cores of line dislocations, where they can reorient their Burgers vectors to become parallel to that of the line dislocation and finally be absorbed.

\section{The development of finger loops}

Finger loops are formed by the coalescence of overlapping large interstitial loops, Details of the coalescence mechanism remain unclear. It probably involves both climb and glide.

Attempts to model loop coalescence by R. Novokshanov (private communication) by dislocation dynamic simulations are in an early stage. The modeling done so far is only for edge loops. This has shown that when hexagonal edge loops overlap in the $\mathrm{z}$ (foil normal) direction they can coalesce by the glide of segments on their joint slip plane. This leads to a stepped habit plane. This may be relevant in understanding how large finger loops can form without intersecting the foil surface - they may not lie entirely on a single habit plane, but would be stepped. The smaller constituent loops may initially have large edge components, but the average habit plane is close to the foil plane. Further simulations better reflecting the geometry of our experiments are in progress.

Other aspects of the development of finger loops also remain unclear. It would seem that


develop into elongated loops? The tendency for such loops to align parallel to each other and close to $<110>$ directions is presumably a consequence of their elastic interaction. But why should the favoured variant be such that the resulting elongated loops tend to lie along the foil thickness gradient (ie pointing towards the hole in the foil)? This may be a consequence of local stresses produced by bending, but at present we have no detailed answer to this question.

\section{The effect of irradiation temperature and $\mathrm{Cr}$ content}

Damage development at RT in UHP Fe seemed to follow the same pattern as at $300^{\circ} \mathrm{C}$ except that complex damage structures developed at somewhat higher doses. Damage development in the $\mathrm{Fe} 8 \% \mathrm{Cr}$ alloy seemed to show the same qualitative pattern as in UHP Fe. This suggests that damage processes remain essentially unchanged. At low doses in $300^{\circ} \mathrm{C}$ irradiations, loop sizes in Fe $8 \% \mathrm{Cr}$ and

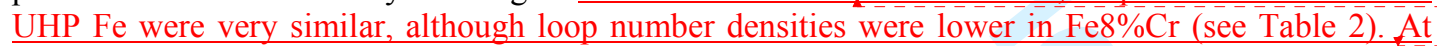
higher doses, loop strings formed on a finer scale and this led to a finer distribution of resolvable large loops, smaller maximum loop sizes and a larger loop number density This might be a consequence of a lower mobility of small loops in $\mathrm{Fe} 8 \% \mathrm{Cr}$ compared with pure Fe. I.

\section{Conclusions}

1. We have studied damage development under $150 \mathrm{keV} \mathrm{Fe}^{+}$ion irradiation in UHP Fe and an $\mathrm{Fe} 8 \% \mathrm{Cr}$ alloy, Initially isolated small dislocation loops formed, as described in Part 1.

2. At doses greater than about $2 \times 10^{18}$ ions $\mathrm{m}^{-2}(\sim 1 \mathrm{dpa})$ more complex microstructures developed in thicker regions of the foils, seeming to involve cooperative alignment and interaction of smaller loops. The exact mechanism by which this occurred is still unclear.
Deleted: 9

Deleted: It is clear from our experiments that large $\mathrm{f}$

Deleted: develop

Deleted: neighboring

Deleted: smaller

Deleted: when they overlap
Deleted: pure

Deleted: pure

Formatted: Superscript

Deleted: The main effect of $\mathrm{Cr}$ seems to be a somewhat

Deleted: finer distribution of

Deleted: , and consequently a

Deleted:

Deleted:

Deleted: ๆ

Deleted: s 
3. In UHP Fe irradiated at $300^{\circ} \mathrm{C}$ the damage developed into resolvable interstitial loops with $1 / 2<111>$ Burgers vectors. By a dose of $2 \times 10^{19}$ ions $\mathrm{m}^{-2}$ (13 dpa ), large (several hundred $\mathrm{nm}$ ) finger-shaped loops had developed in some areas by the growth and subsequent coalescence of smaller loops. These loops had large shear components.

4. Similar strings of loops developed in UHP Fe irradiated at RT, but these had not developed further by the end of the experiment at $1.6 \times 10^{19}$ ions $\mathrm{m}^{-2}(\sim 10 \mathrm{dpa})$.

5. Damage development was similar in $\mathrm{Fe} 8 \% \mathrm{Cr}$, although the finger-shaped loops seen in the $300^{\circ} \mathrm{C}$ irradiation were less developed and not as well aligned as in UHP Fe.

6. A plausible sequence of events leading to the observed damage structures has been described. It has been suggested that the presence of small glissile clusters is important in determining the evolution of damage structures. 


\section{Acknowledgements}

The IVEM-Tandem Facility (within the Electron Microscopy Center at ANL) is supported by the US DOE Office of Science and operated under contract no. DE-AC02-06CH11357 by UChicago Argonne, LLC. We thank Dr. A. Liu and P Baldo of Argonne National Lab for their help in using this facility. . Part of this work was funded by the UKAEA, Culham Science Centre. Ex-situ experiments on UHP Fe were supported by the European Commission in the framework of the PERFECT Project. We also thank Prof. J. Le Coze of the École de Mines de Saint Étienne for the provision of UHP iron and Prof S. G. Roberts and Dr. S. L. Dudarev for helpful discussions 


\section{References}

1. Z. Yao, M. Hernandez-Mayoral, M. L. Jenkins and M. A. Kirk, Phil. Mag. this issue (2008)

2. M L Jenkins and M A Kirk, Characterisation of Radiation Damage by Transmission Electron Microscopy, Institute of Physics Series in Microscopy in Materials Science (Series Editors, B Cantor and M J Goringe) ISBN 075030748 X (hbk) (2001)

3. I.M. Robertson, M.A. Kirk, Wayne E. King, Scripta Met. 18317 (1984)

4. M.A. Kirk, I.M. Robertson, M.L. Jenkins, C.A. English, T.J. Black, and J.S. Vetrano. J. Nucl. Mater.149 21 (1987)

5. S. J. Zinkle, B.N. Singh. J. Nucl. Mater. 351269 (2006).

6. A F Calder and D J Bacon, J. Nucl. Mater. 20725 (2000)

7. Yu. N. Osetsky, D. J. Bacon, B. N. Singh, B. Wirth, J. Nucl. Mater. 307-311 852 (2002)

8. A F. Calder, D. J. Bacon, A. V. Barashev and Yu. N. Osetsky, Phil. Mag. Lett. 88, 43(2008)

9. B von Guerard, D Grasse and J Peisl, Phys. Rev. Lett, 44262 (1980)

10. M.L Jenkins, C.A English and B L Eyre, Phil. Mag., 38 (1978).

11. H. Abe, N. Sekimura and T. Tadokoro, Mat. Trans. 46, 433 (2005)

12. J.L.Brimhall and B. Mastel, Rad. Effects 3, 201 (1970)

13. M. Edrup, B. L. Singh, S.J . Zinkle et al J. Nucl. Mater. 307-311 912 (2002)

14. B.N. Singh, J. H. Evans, A, Horsewell et al J. Nucl. Mater. 258865 (1998)

15. M. Wen, N.M.Ghoniem and B.N.Singh, Phil. Mag. 85, 2561 (2005)

16. R.S.Barnes, J.Phys. Soc. Japan. Suppl III 18305 (1963)

17. M Gilbert, S. L. Dudarev, P. Derlet, and D. G. Pettifor submitted to Phil. Mag (2007) 
Tables

\begin{tabular}{|cc|c|c|c|c|c|c|c|}
\hline $\mathbf{g}$ & $\backslash \mathbf{b}$ & $1 / 2[111]$ & $1 / 2[\overline{1} 11]$ & $1 / 2[1 \overline{1} 1]$ & $1 / 2[11 \overline{1}]$ & {$[100]$} & {$[010]$} & {$[001]$} \\
\hline $1 \overline{1} 0$ & 0 & 1 & 1 & 0 & 1 & 1 & 0 \\
\hline$\overline{1} 01$ & 0 & 1 & 0 & 1 & 1 & 0 & 1 \\
\hline $01 \overline{1}$ & 0 & 0 & 1 & 1 & 0 & 1 & 1 \\
\hline
\end{tabular}

\begin{tabular}{|l|l|l|l|l|l|l|l|}
\hline 002 & 1 & 1 & 1 & 1 & 0 & 0 & 2 \\
\hline 110 & 0 & 1 & 1 & 0 & 1 & 1 & 0 \\
\hline
\end{tabular}

\begin{tabular}{|l|l|l|l|l|l|l|l|}
\hline $0 \overline{1} 1$ & 0 & 0 & 1 & 1 & 0 & 1 & 1 \\
\hline$\overline{1} 12$ & 1 & 2 & 0 & 1 & 1 & 1 & 2 \\
\hline$\overline{1} 21$ & 1 & 2 & 1 & 0 & 1 & 2 & 1 \\
\hline
\end{tabular}

\begin{tabular}{|l|l|l|l|l|l|l|l|}
\hline $10 \overline{1}$ & 0 & 1 & 0 & 1 & 1 & 0 & 1 \\
\hline $2 \overline{1} 1$ & 1 & 1 & 2 & 0 & 2 & 1 & 1 \\
\hline $1 \overline{1} 2$ & 1 & 0 & 2 & 1 & 1 & 1 & 2 \\
\hline
\end{tabular}

Table 1: $|\mathbf{g . b}|$ table for reflections near [111], [110], [311] and [131] poles. 


\begin{tabular}{|c|c|c|c|c|c|c|}
\hline \multirow[t]{2}{*}{ Doses (ions $\mathrm{m}^{-2}$ ) } & \multicolumn{2}{|c|}{$\frac{\frac{\text { Average size }(\mathrm{nm})}{\text { (total number of measured }}}{\text { loops) }}$} & \multicolumn{2}{|c|}{$\frac{\text { Maximum size }}{(\mathrm{nm})}$} & \multicolumn{2}{|c|}{$\frac{\text { loop density }}{\left(\mathrm{x} 10^{14} \mathrm{~m}^{-2}\right)}$} \\
\hline & $\underline{\text { UHP Fe }}$ & $\underline{\mathrm{Fe} 8 \mathrm{Cr}}$ & $\underline{\mathrm{UHP} F e}$ & $\underline{\mathrm{Fe} 8 \mathrm{Cr}}$ & $\underline{\mathrm{UHP}} \mathrm{Fe}$ & $\underline{\mathrm{Fe} 8 \mathrm{Cr}}$ \\
\hline$\underline{1 \times 10^{18}(0.6 \mathrm{dpa})}$ & $\frac{2.95 \pm 0.07}{\underline{(1544)}}$ & $\frac{3.4 \pm 0.03}{\underline{(391)}}$ & $\underline{9}$ & $\underline{8}$ & $\underline{5.16 \pm 1.72}$ & $\underline{2.22 \pm 0.5}$ \\
\hline$\underline{2 \times 10^{18}(1.3 \mathrm{dpa})}$ & $\frac{5.34 \pm 0.09}{(2358)}$ & & $\underline{32}$ & & $\underline{6.85 \pm 2.05}$ & \\
\hline$\underline{5 \times 10^{18}(3.2 \mathrm{dpa})}$ & & $\frac{4,9 \pm 0.3}{(402)}$ & & $\underline{16}$ & & $\underline{3.58 \pm 1}$ \\
\hline$\underline{1 \times 10^{19}(6.5 \mathrm{dpa})}$ & $\frac{9.7 \pm 0.2}{(2205)}$ & $\frac{5.2 \pm 0.5}{(1381)}$ & $\underline{92}$ & $\underline{20}$ & $\underline{7.05 \pm 2.32}$ & $\underline{7.40 \pm 2.14}$ \\
\hline$\underline{2 \times 10^{19}(13 \mathrm{dpa})}$ & $\frac{10.4 \pm 0.3}{\frac{4.46 \pm 0.05}{(2459)}}$ & $\frac{5.5 \pm 0.2}{\underline{(1589)}}$ & $\underline{224}$ & $\underline{24}$ & $\underline{2.46 \pm 0.7}$ & $\underline{9.68 \pm 2.61}$ \\
\hline
\end{tabular}

Table 2: Quantitative data on sizes and densities of dislocation loops in UHP-Fe and $\mathrm{Fe} 8 \% \mathrm{Cr}$ irradiated at $300^{\circ} \mathrm{C}$

\begin{tabular}{l} 
Deleted: $\uparrow$ \\
Foses (ions $\mathrm{m}^{-2}$ ) \\
\hline Formatted: Font color: Auto \\
\hline Formatted Table \\
\hline Formatted: Font color: Auto \\
\hline Formatted: Font color: Auto \\
\hline Formatted: Font color: Auto \\
\hline Formatted: color: Auto \\
\hline Formatted: Font color: Auto \\
\hline Formatted: Font color: Auto \\
\hline Formatted: Font color: Auto \\
\hline Formatted: Superscript \\
\hline
\end{tabular}




\section{Figure captions}

Figure 1: Damage development in UHP Fe irradiated with $150 \mathrm{keV} \mathrm{Fe}^{+}$ions at $300^{\circ} \mathrm{C}$ seen in an ex-situ experiment. BFK images taken with $\mathbf{g}=1 \overline{1} 0$ at doses (a) $2 \times 10^{18}$ ions $^{-2}(\sim 1.3$ dpa); (b) $10^{19}$ ions $\mathrm{m}^{-2}(\sim 6.5 \mathrm{dpa})$; (c) $2 \times 10^{19}$ ions $\mathrm{m}^{-2}$ ( 13 dpa); Images (a) and (c) were obtained with the foil oriented near (111), and image (b) was taken near the [001] pole.

Figure 2: $\quad$ Size distributions of loops in UHP Fe irradiated with $150 \mathrm{keV} \mathrm{Fe}^{+}$ions at $300^{\circ} \mathrm{C}$ seen in an ex-situ experiment.

Figure 3: Development of damage structures in UHP Fe irradiated with $150 \mathrm{keV} \mathrm{Fe}^{+}$ions at $300^{\circ} \mathrm{C}$. Note the change of scale in the bottom micrographs. Weak-beam micrographs taken with $\mathbf{g}=110$. Doses are (a) $10^{18}$ ions $\mathrm{m}^{-2}(0.6 \mathrm{dpa})(\mathrm{b}) 2 \times 10^{18}$ ions $\mathrm{m}^{-2}(1.2 \mathrm{dpa})$; (c) $10^{19}$ ions $\mathrm{m}^{-2}(6.5 \mathrm{dpa})(\mathrm{d}), 1.6 \times 10^{19}$ ions m$^{-2}(10.4 \mathrm{dpa})$.

Figure 4 The formation of resolvable loops from loop strings in UHP Fe irradiated with $150 \mathrm{keV}$ $\mathrm{Fe}^{+}$ions at $300^{\circ} \mathrm{C}$. This is a series of frames extracted from video 3 at doses between

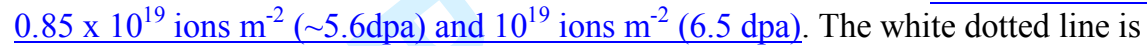
drawn to the left of the feature of interest as a guide to the eye. Weak-beam images in $\mathbf{g}=1 \overline{10}$ shown as negatives.

| Figure 5. A series of frames grabbed from a video recording, showing loop growth and coalescence in UHP Fe irradiated with $150 \mathrm{keV} \mathrm{Fe}^{+}$ions at $300^{\circ} \mathrm{C}$ over a dose range from about $10^{19}$ ions $\mathrm{m}^{-2}(\sim 6.5 \mathrm{dpa})$ to about $1.6 \times 10^{19}$ ions $\mathrm{m}^{-2}(\sim 10 \mathrm{dpa})$. Weak-beam micrographs taken with $\mathbf{g}=110$. The projection of the Burgers vector of the loops is shown $_{s,}$

| Figure 6 Contrast experiment in UHP Fe irradiated with $150 \mathrm{keV} \mathrm{Fe}$ ions to a dose of $1.6 \times 10^{19}$ ions $\mathrm{cm}^{-2}(\sim 10 \mathrm{dpa})$ at $300^{\circ} \mathrm{C}$. The large loops have $1 / 2<111>$ Burgers vectors. The

Thompson tetrahedron indicates the $(111]$ foil orientation for the $\{110\}$ micrographs (a)(d). The 002 micrograph (e) was taken close to the [110] pole. See the text for details.

| Figure 7 Stereogram for the contrast experiment shown in Figure 8. The approximate position of the foil normal is marked FN. Loop set A has Burgers vector $\mathbf{b}= \pm 1 / 2[\overline{1} 11]$, set $B$ has $\mathbf{b}= \pm 1 / 2[1 \overline{1} 1]]$ and set $C$ has $\mathbf{b}= \pm 1 / 2[11 \overline{1}]$.

Figure 8 Possible voids in UHP Fe irradiated at $300^{\circ} \mathrm{C}$ to a dose of $10^{19} \mathrm{~m}^{-2}$ (about $6.5 \mathrm{dpa}$ ). Thefeatures ringed appear as black dots in the overfocussed image on the left, and white dots in the underfocussed image, consistent with the contrast expected of small voids.

| Figure 9

Development of an inhomogeneous damage structure in thicker areas of foil in UHP Fe irradiated with $150 \mathrm{keV} \mathrm{Fe}$ ions at to a dose of $10^{19} \mathrm{~m}^{-2}$ (about $6.5 \mathrm{dpa}$ ) at RT. Strings of loops are seen in thicker areas, lining up more or less parallel to projection of the [110] direction. The inset shows the strings at higher magnification. Contrast

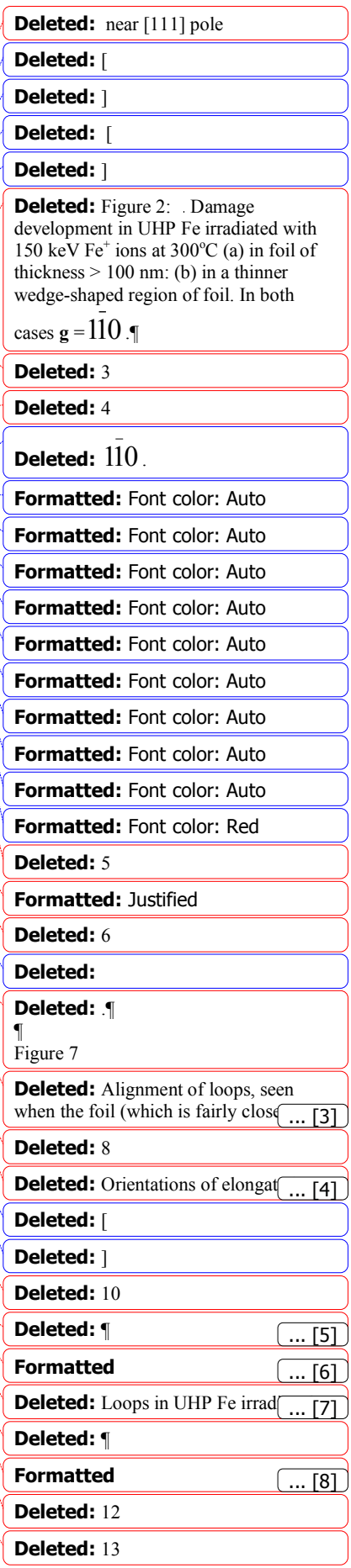


experiments showed that the loops in a given string all have the same $1 / 2<111>$ Burgers vector. In thin areas of foil, to the bottom right, only isolated loops are seen. Most of these have $<100>$ Burgers vectors.

Figure 10 Evolution of microstructure with dose in $\mathrm{Fe} 8 \% \mathrm{Cr}$ irradiated with $150 \mathrm{keV} \overline{\mathrm{Fe}}$ ions at $300^{\circ} \mathrm{C}$ to doses of : (a) $10^{19} \mathrm{~m}^{-2}(\sim 6.5 \mathrm{dpa}) ;(\mathrm{b}) 2 \times 10^{19} \mathrm{~m}^{-2}$ ( $\left.\sim 13 \mathrm{dpa}\right)$. Micrograph (a) was taken under weak-beam conditions, and micrograph $(\mathrm{b})$ under kinematical bright-field conditions.

Figure $11 \quad$ Evolution of microstructure with dose in Fe $8 \% \mathrm{Cr}$ irradiated at RT with $150 \mathrm{keV} \mathrm{Fe}^{+}$ions to doses of $(\mathrm{a}) 10^{19-} \mathrm{m}^{-2}(\sim 6.5 \mathrm{dp})$; and (b) $1.9 \times 10^{19}$ ions $\mathrm{m}^{-2}(\sim 12 \mathrm{dpa})$ Micrograph $\mathrm{a}$ (a) was taken under weak-beam conditions, and (b) under kinematical bright-field conditions.
Deleted: (see Figure 14)

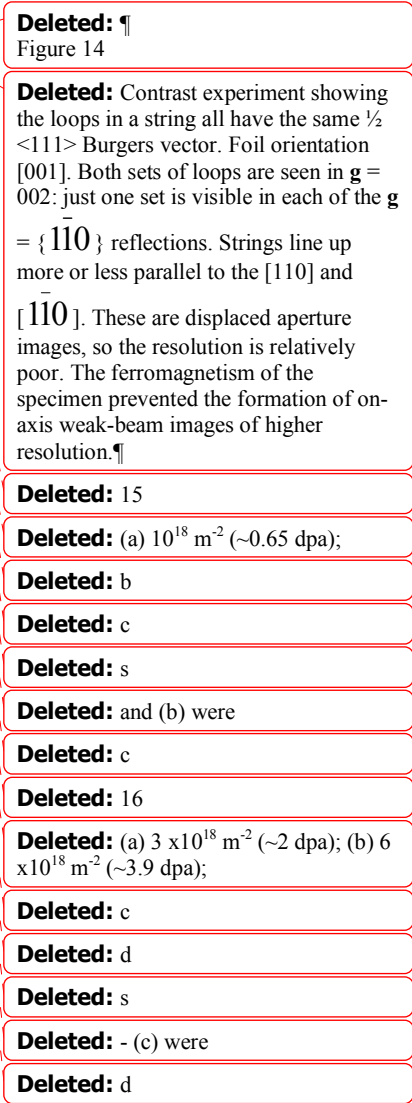

the loops in a string all have the same $1 / 2$

$<111>$ Burgers vector. Foil orientation

002: just one set is visible in each of the $\mathbf{g}$

$=\{110\}$ reflections. Strings line up or less parallel to the [110] and latively

resolution.

Deleted:

Deleted: and (b) were

Deleted: (a) $3 \times 10^{18} \mathrm{~m}^{-2}(\sim 2 \mathrm{dpa})$; (b) 6 $\times 10^{18} \mathrm{~m}^{-2}(\sim 3.9 \mathrm{dpa})$;

Deleted:

Deleted:

d: - (c) were 
Figure 7 shows loop alignment more clearly. Here the same specimen seen in Figure 6 has been tilted to [001], and a nearby area showing more organized loop alignment has been imaged under BFK conditions. Lines of loops can be seen along or close to the [110 ] direction running diagonally from the top left, and some have coalesced to form fingershaped loops, similar to those seen in figure 1(b). These loops belong to the set designated $\mathrm{A}$ in the Burgers vector analysis described below. The [110] direction along which they align lies close to the plane of the foil. The tendency for alignment shown in this micrograph may be exaggerated because the foil has been tilted such that the loop habit plane, which is close to the plane of the foil, is inclined, see below. There is some evidence for more limited alignment in the perpendicular [110], direction which is steeply inclined to the foil plane, suggesting the formation of a raft-like structure.

Although there

Page 15: [2] Deleted

Mike Jenkins

7/11/2008 9:16:00 AM

\begin{tabular}{|c|c|c|c|}
\hline Doses $\left(\right.$ ions $\left.\mathrm{m}^{-2}\right)$ & $\begin{array}{c}\text { Average size }(\mathrm{nm}) \\
\text { (total number of } \\
\text { measured loops) }\end{array}$ & $\begin{array}{c}\text { Maximum size } \\
(\mathrm{nm})\end{array}$ & $\begin{array}{c}\text { loop density } \\
\left(\times 10^{14} \mathrm{~m}^{-2}\right)\end{array}$ \\
\hline $1 \times 10^{18}(0.6 \mathrm{dpa})$ & $2.95 \pm 0.07(1544)$ & 9 & $5.16 \pm 1.725 .16$ \\
\hline $2 \times 10^{18}(1.3 \mathrm{dpa})$ & $5.34 \pm 0.09(2358)$ & 32 & $6.85 \pm 2.056 .85$ \\
\hline $1 \times 10^{19}(6.5 \mathrm{dpa})$ & $9.7 \pm 0.2(2205)$ & 92 & $7.05 \pm 2.327 .05$ \\
\hline $2 \times 10^{19}(13 \mathrm{dpa})$ & $\begin{array}{l}10.4 \pm 0.3 \\
4.46 \pm 0.05\end{array}$ & 224224 & $2.46 \pm 0.72 .46$ \\
\hline
\end{tabular}

Page 16: [3] Deleted

Mike Jenkins

6/20/2008 12:31:00 PM

Alignment of loops, seen when the foil (which is fairly close to [111] in orientation) is tilted close to the [001] pole, and imaged in under bright-field kinematical conditions with $\mathbf{g}=200$. UHP-Fe irradiated at $300^{\circ} \mathrm{C}$ with $150 \mathrm{keV} \mathrm{Fe}{ }^{+}$to $1.6 \times 10^{19}$ ions $\mathrm{m}^{-2}(\sim 10 \mathrm{dpa})$.

Page 16: [4] Deleted Mike Jenkins 6/20/2008 12:32:00 PM

Orientations of elongated loops at various positions relative to the hole in the TEM specimen. The foil thickness in the wedge-shaped specimen increases radially.

Figure 9

Figure 11 
Indent: Left: 0", First line: 0"

Page 16: [7] Deleted

Mike Jenkins

6/20/2008 12:32:00 PM

Loops in UHP Fe irradiated with $150 \mathrm{keV} \mathrm{Fe}^{+}$ions to $1.6 \times 10^{19}$ ions $\mathrm{m}^{-2}(\sim 10 \mathrm{dpa})$. BFK micrographs taken with $\mathbf{g}=1 \overline{10}$. Micrographs (a) and (b) show a stereo pair, taken near the [111] and [110] poles respectively. Micrograph (c) is the same as (a) but has been shrunk perpendicular to $\mathbf{g}$ to simulate the foreshortening caused by tilting.

Page 16: [8] Formatted

Indent: Left: 0", Hanging: 1"
Mike Jenkins

6/20/2008 12:38:00 PM 


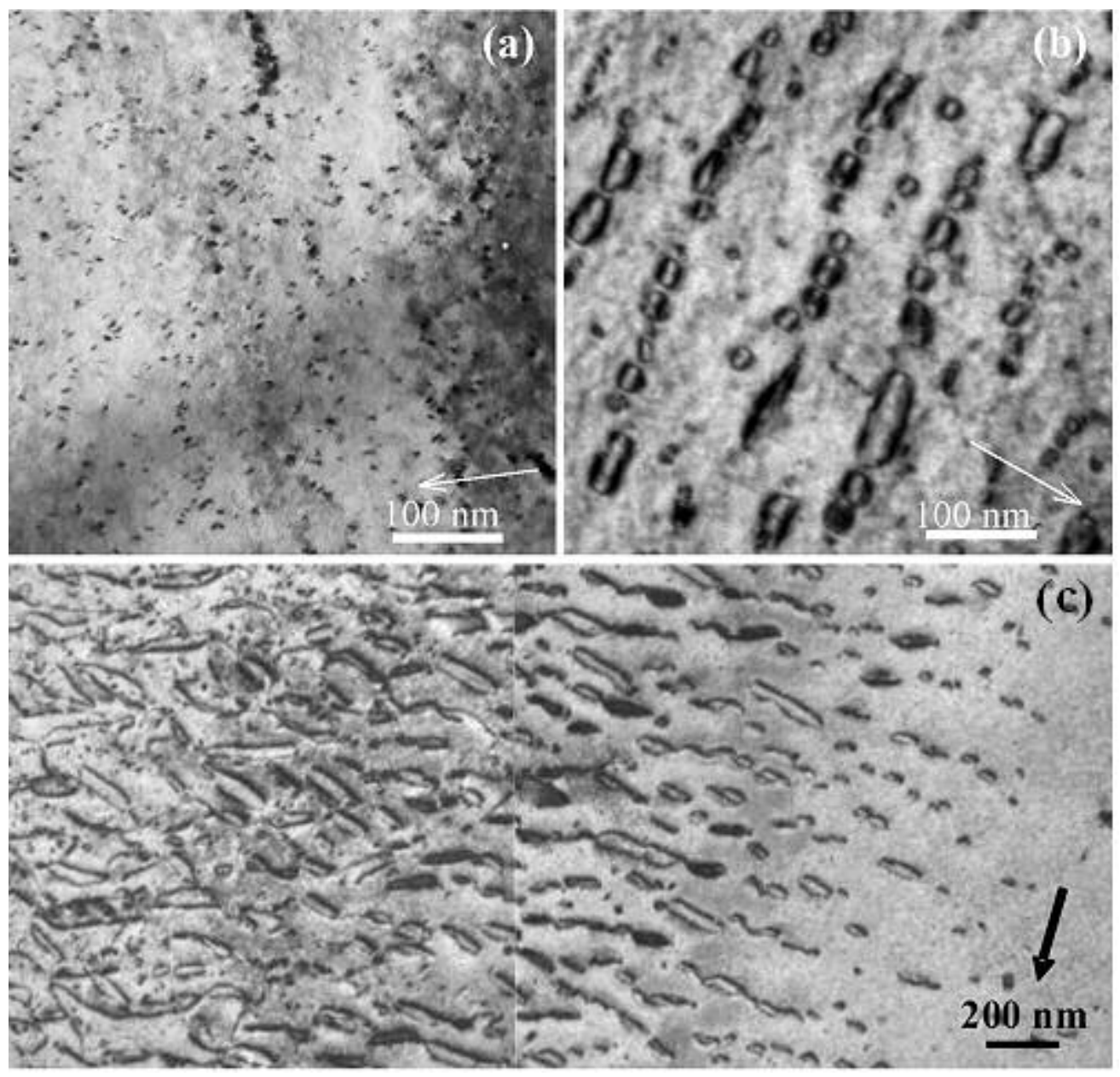

Figure 1

$42 \times 40 \mathrm{~mm}(300 \times 300 \mathrm{DPI})$ 



Figure 2 


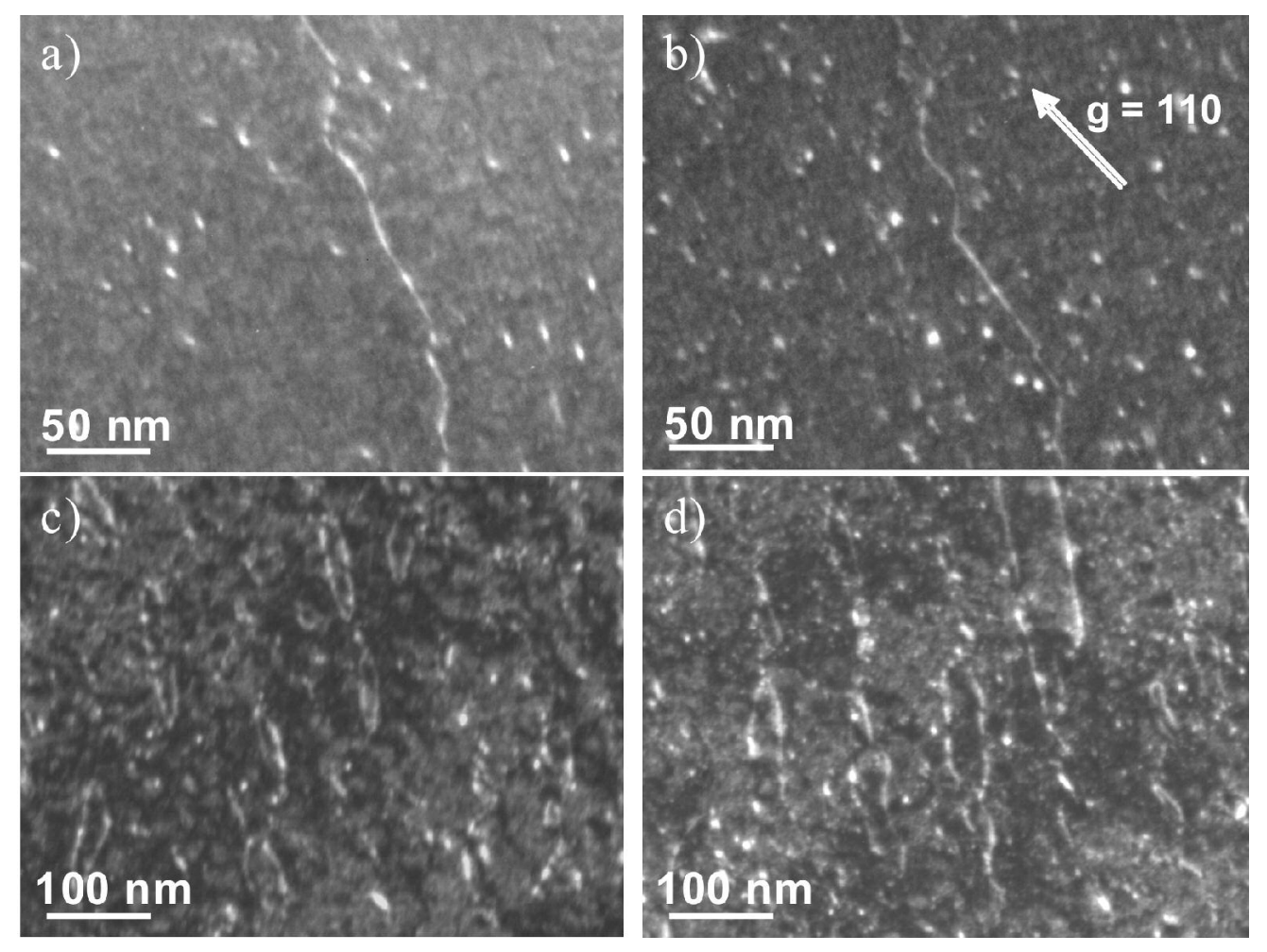

Figure 3 

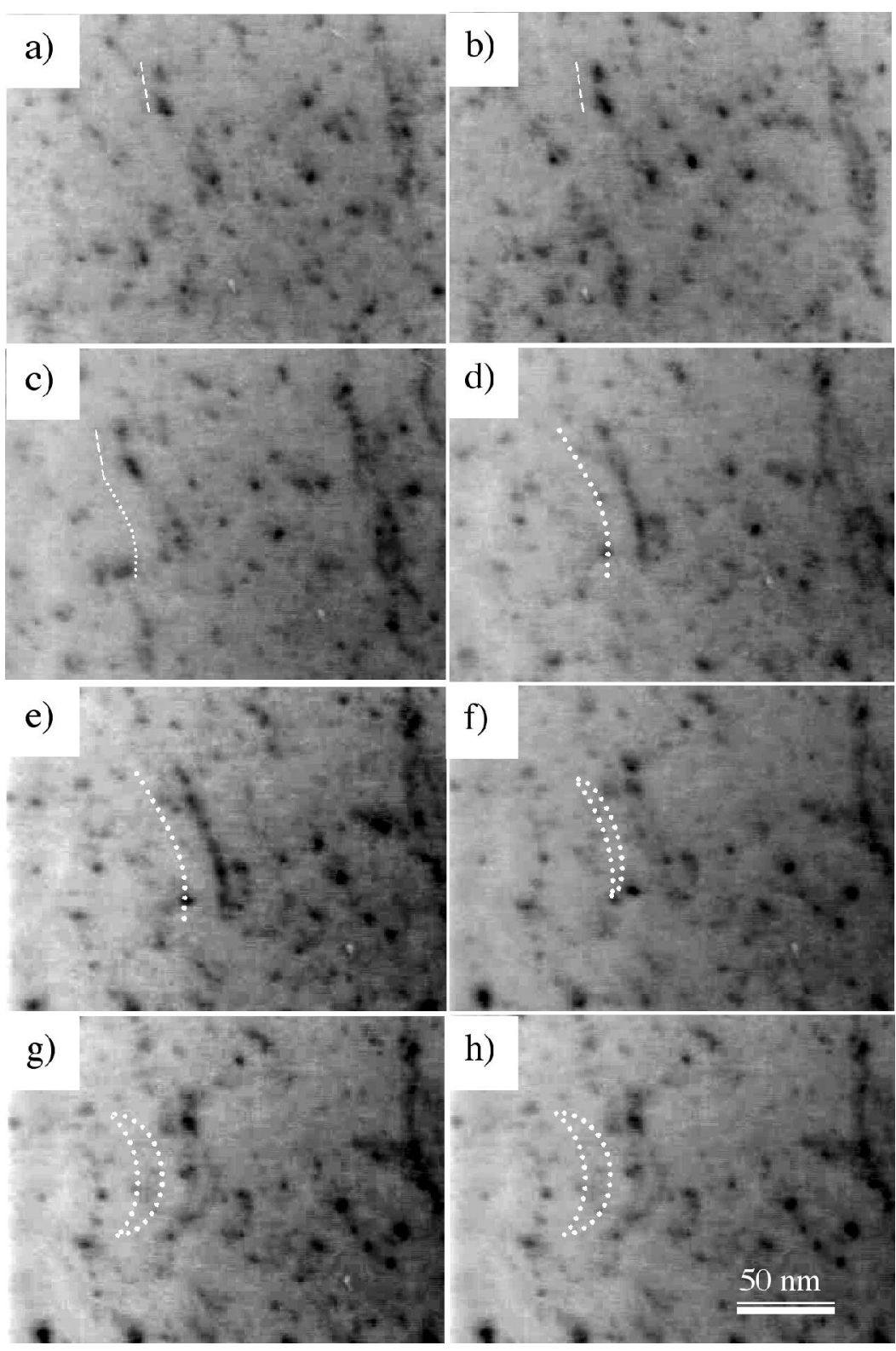

Figure 4

$115 \times 172 \mathrm{~mm}(300 \times 300$ DPI $)$ 


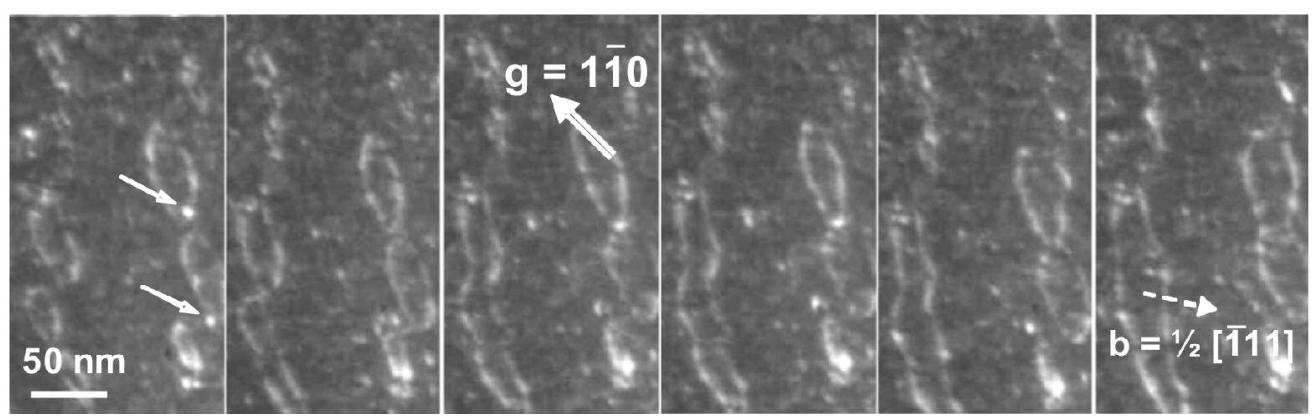

Figure 5 

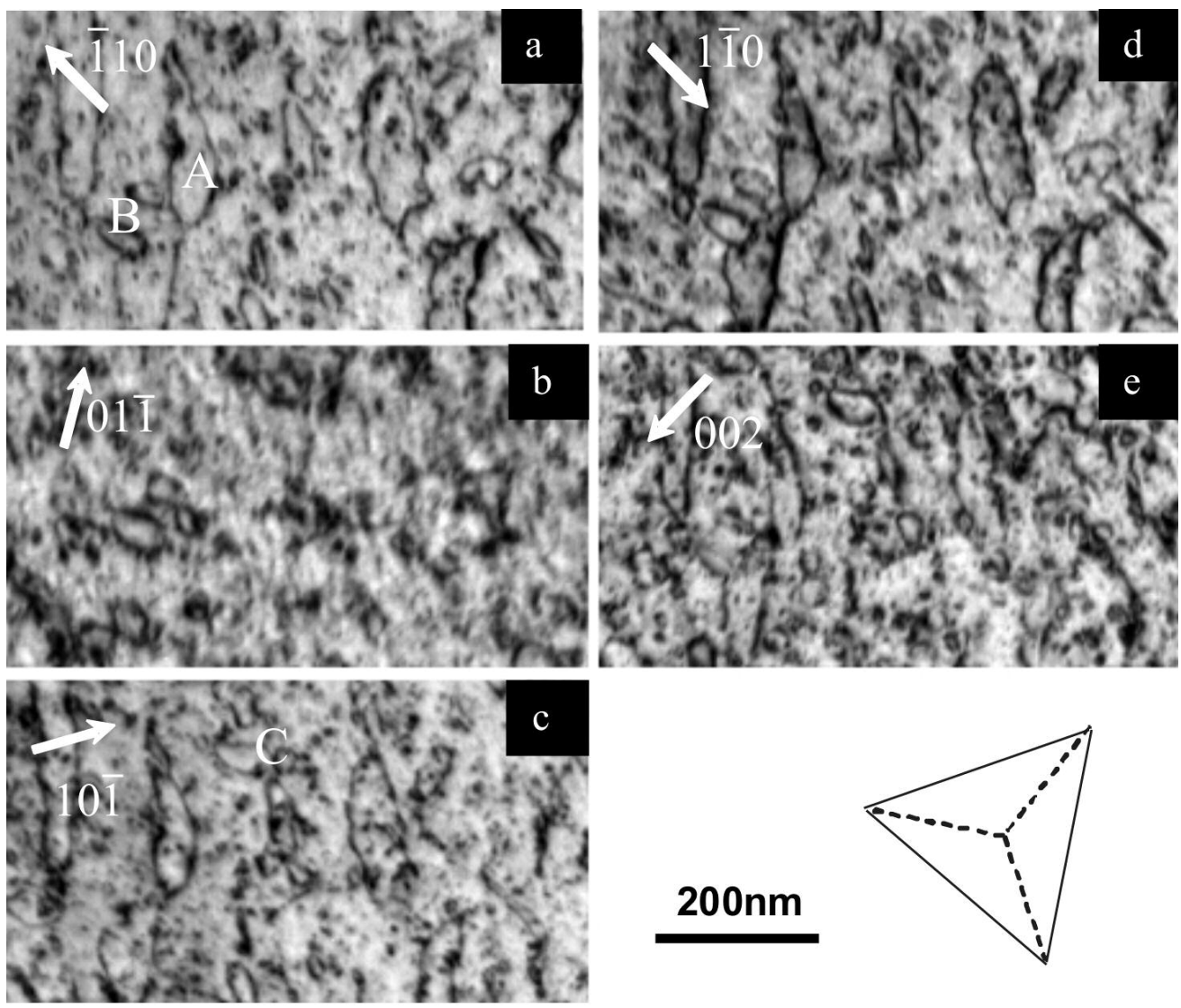

Figure 6 


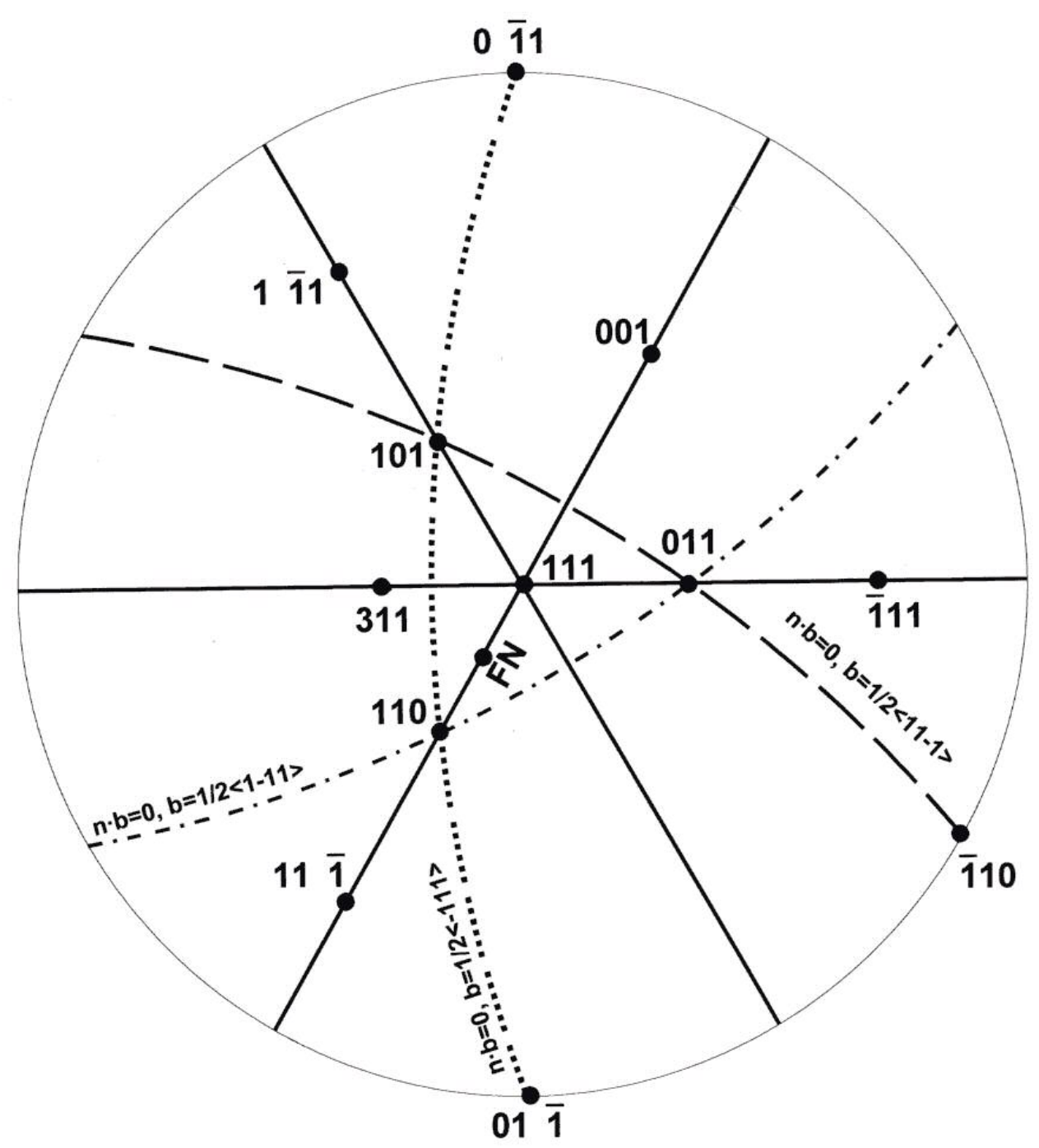

Figure 7

$153 \times 169 \mathrm{~mm}(150 \times 150 \mathrm{DPI})$ 


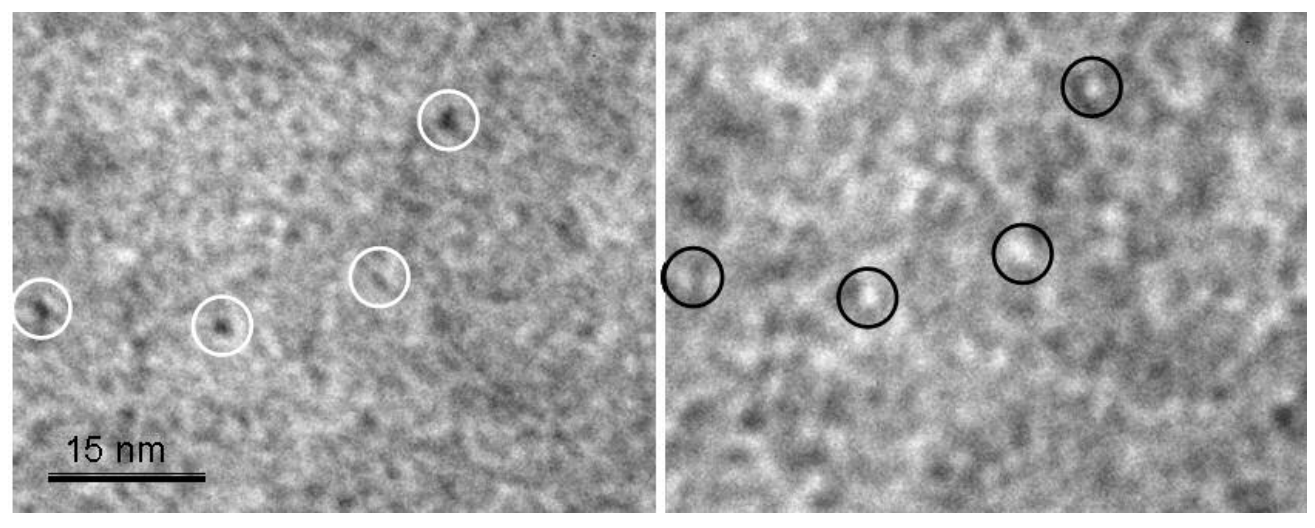

Figure 8

$297 \times 114 \mathrm{~mm}(72 \times 72$ DPI $)$ 


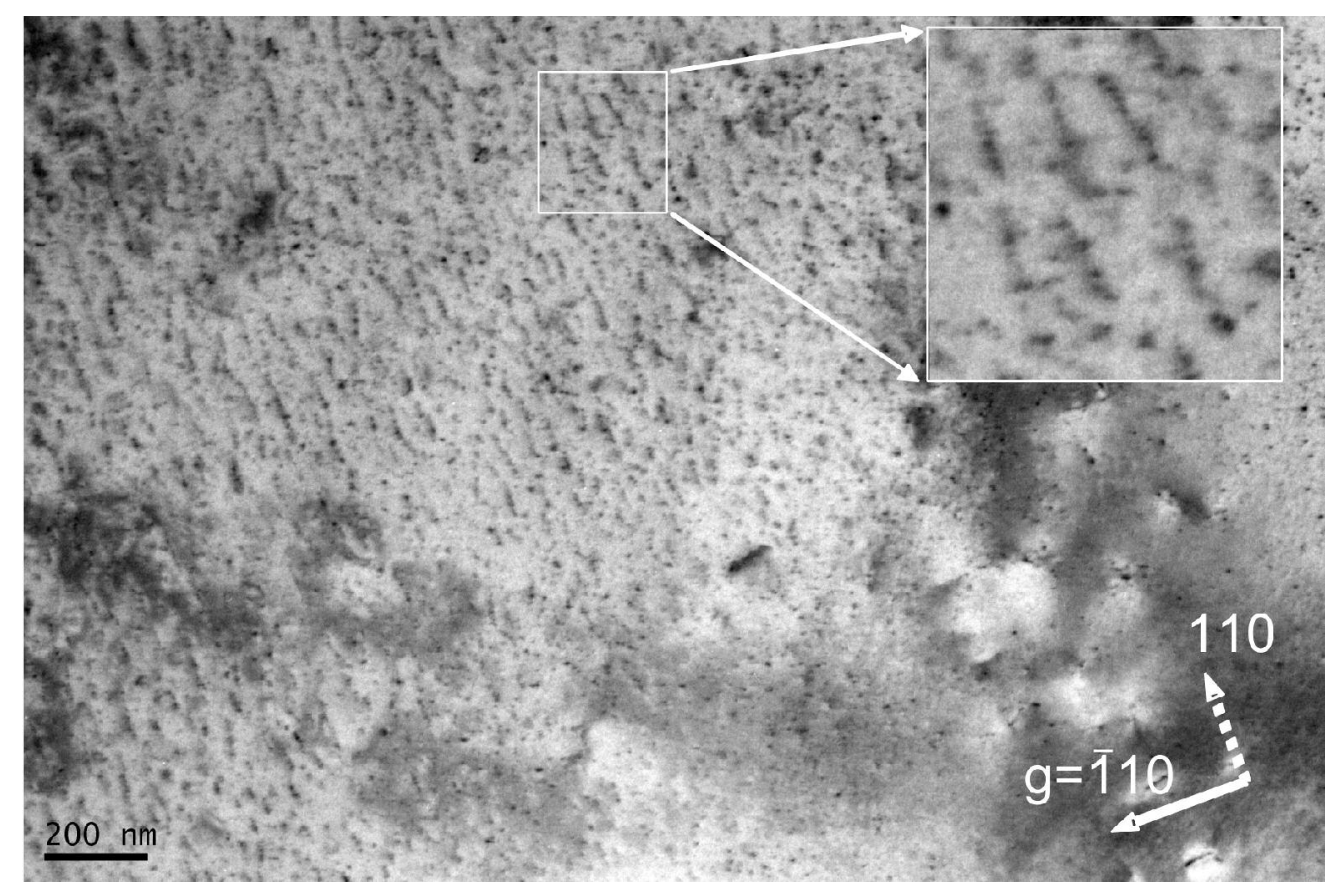

Figure 9 

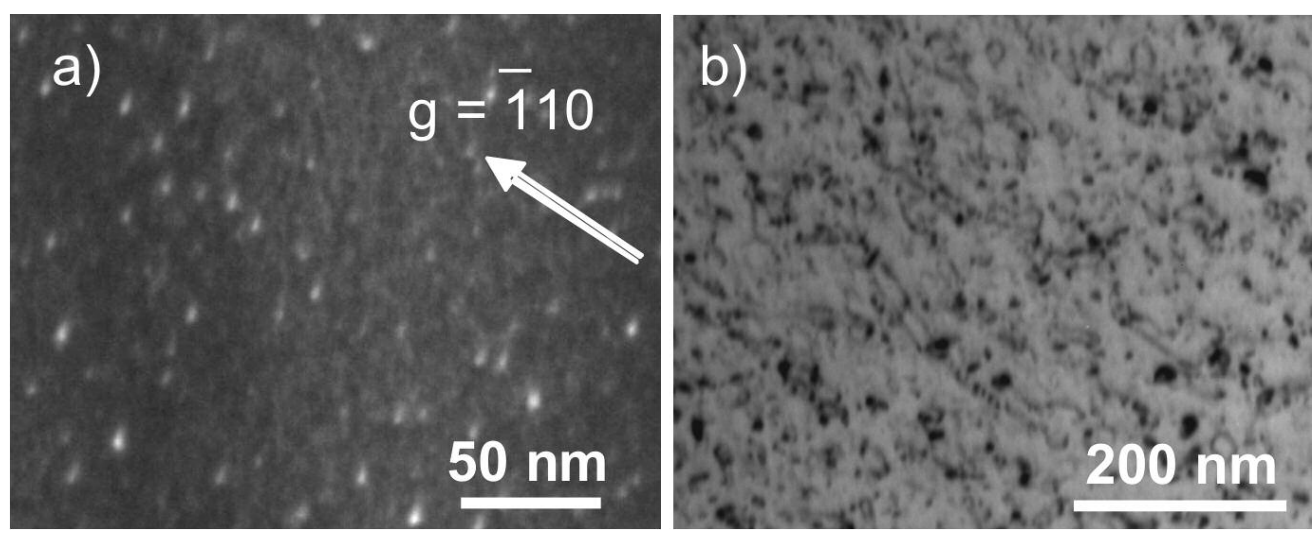

Figure 10 


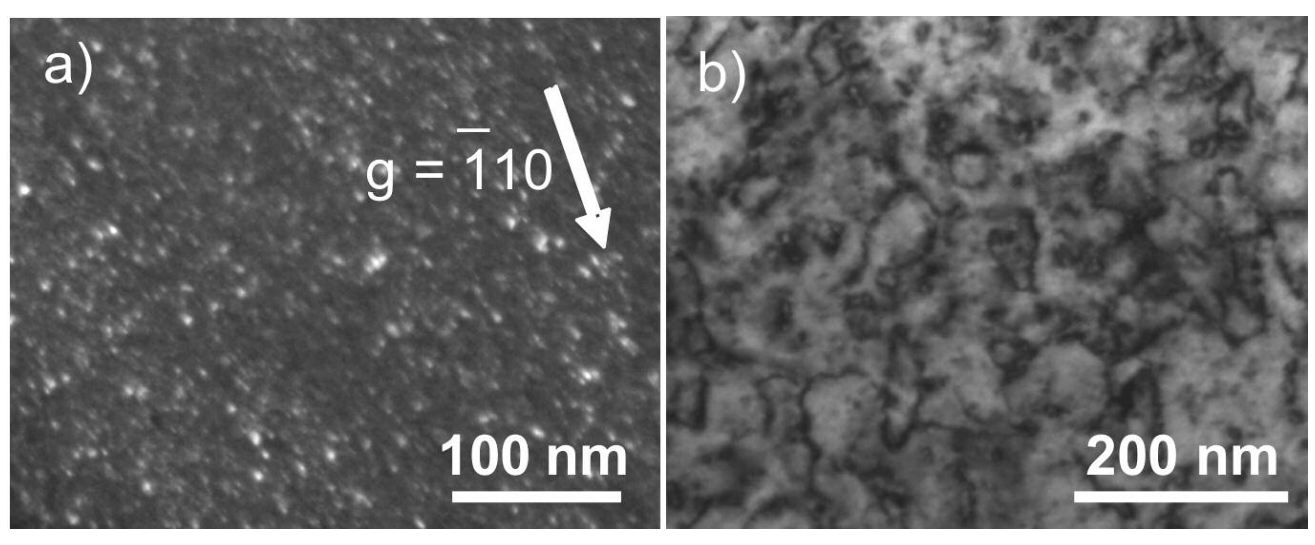

Figure 11 